\title{
The podiatric surgery theatre environment in the UK; is it conducive to learning? A quantitative study using the surgical theatre educational environment measure (STEEM)
}

Thomas Austen ${ }^{1,2^{*}}$ and Simon Otter ${ }^{3}$

\begin{abstract}
Background: In 2015 the Health and Care Professions Council (HCPC) reported that annotation of the register for podiatric surgery would improve the way in which risks are currently managed. The academic institutions provide the teaching environment for the 'learnt' Diploma in principles of podiatric surgery however the podiatric surgery departments facilitate the production of the next generation of podiatric surgeons. This research aimed to identify the major elements that contribute to the educational environment, and find and utilise a valid assessment tool which could identify discrete areas to be targeted for improvement as well as being used for monitoring of the environment.
\end{abstract}

Methods: A quantitative study using the Surgical Theatre Educational Environment Measure (STEEM) via an online tool was utilised for podiatrists working within podiatric surgery, podiatric surgical trainees and podiatric surgeons working towards the Certificate of Completion of Podiatric Surgery Training (CCPST) with a view to assessing the educational environment within the podiatric surgical theatre in the UK.

Results: $16 / 33$ responses with a response rate of $48.4 \%$ the overall STEEM mean score was 122/160. Four subscales included teaching and training, learning opportunities, atmosphere, and workload/supervision/support were measured. The overall mean score of $76.73 \%$ suggests the learning environment may be considered satisfactory; however, areas for potential improvement are identifiable. Results reveal strengths such as a non-discriminatory surgical theatre atmosphere on racial grounds.

Conclusions: Perception was of a very satisfactory 'Atmosphere' within the theatre environment and a very satisfactory 'opportunity to assist' within the podiatric surgery theatre environment. The STEEM has potential to be applied further as a quality assessment tool whose results could be used to demonstrate part of the HCPC standards.

Keywords: Podiatric surgery, Surgical theatre educational environment, Podiatric surgery teaching and learning

\footnotetext{
* Correspondence: info@podplus.co.uk; t.g.austen@brighton.ac.uk

'Podplus Ltd, The Julie Rose Stadium, Ashford, Kent TN24 9QX, UK

${ }^{2}$ School of Health Sciences, University of Brighton, Robert Dodd, Darley Road,

Eastbourne BN20 7UR, UK

Full list of author information is available at the end of the article
}

(c) The Author(s). 2019 Open Access This article is distributed under the terms of the Creative Commons Attribution 4.0 International License (http://creativecommons.org/licenses/by/4.0/), which permits unrestricted use, distribution, and reproduction in any medium, provided you give appropriate credit to the original author(s) and the source, provide a link to the Creative Commons license, and indicate if changes were made. The Creative Commons Public Domain Dedication waiver (http://creativecommons.org/publicdomain/zero/1.0/) applies to the data made available in this article, unless otherwise stated. 


\section{Background}

In 2015 the Health and Care Professions Council (HCPC) reported that annotation of the register for podiatric surgery would improve the way in which risks are currently managed. They published professional standards that should be met to enable annotation. The reasons given for this were that annotation would enable specific standards to be set for podiatric surgery training and practice. Training programmes would be approved and linked to the annotation, providing independent quality assurance. Annotating the Register would provide information to members of the public about who had completed recognised, approved training, supporting informed choices [1].

The learning environment considered for podiatric surgery is a workplace environment rather than a classroom environment with taught lectures. This work environment can include the outpatient clinic with new patient assessments, pre-operative assessments and post-operative reviews, dressing clinics as well as the actual theatre environment.

The podiatric surgery route (Fig. 1) does have a broad framework, and it can be considered that the consultant acts as a mentor to guide the student through this process. The whole process can be seen as formal however due to the nature of the experiential learning, the environment can be considered to be informal [2].

This unstructured format is described as informal learning which has a naturally occurring form of learning based in and around personal experience of situations [3]. This is against formal learning which has been described as having one of a number of characteristics including; having a prescribed learning framework, an organised learning event or package, the presence of a designated teacher or trainer, the award of a qualification or credit and the external specification of outcomes [4].

In their review of workplace learning, Manuti et al. [2] suggest informal learning occurs within environments where the principal objective is not learning. However learning is activated by some anticipated or actual problem which arises. They suggest informal learning could happen as a result of evolving activities such as problem solving, hypothesis testing, mentoring, coaching and job shadowing. This learning requires a mix of individual characteristics to be actioned, notably Beckett and Hager [5] report intellectual curiosity, self-directedness and self-efficacy can be key to the quality of learning within learning environments.

It has also been explained as implicit learning, deliberative learning and reactive learning. Implicit and deliberative being intentional and non-intentional with reactive learning is an 'in between' category, which describes situations where the learning takes place almost spontaneously, rather than planned and is in response to recent, current, or imminent situations without any time being planned or specifically set aside for it [4]. Eraut's [6] work on informal learning in the workplace and Ajjawi and Higgs [7] provide insight into a very unstructured environment. They give insight into the factors that affect learning and how this is communicated in the clinical setting.

Ajjawi and Higgs [7] used a qualitative approach to delve deeply into the way physiotherapists communicate their clinical reasoning to patients as well as more junior physiotherapists. They took a hermeneutic phenomenological approach, essentially getting a human experience view on this subject, to gain their insight. This included observation, written reflective pieces from the subjects and interviews with subsequent analysis. It appeared the methodology was well considered and their specificity within the study of physiotherapists with a speciality may be a restrictive factor limiting its potential for other specialities.

Their findings did suggest a number of themes can affect the learning environment. They suggest the team environment, professional attributes and workplace culture all to be factors that are important. Along with this, incidents and analysis of these incidents including reflective practice appear to be important. They also found that learning to reason and to communicate reasoning are situated, embedded, and enriched in practice itself, suggesting that the learning is best done in the workplace environment.

Eraut [6] uses his previous work in 2000 [4] to consider 'key concepts' of informal learning which are stated as learning from experience, tacit knowledge, transfer of learning and intuitive practice to discuss the factors that he feels are effecting learning in the workplace. He highlights factors which he feels influence learning but does stress their importance will differ in different situations with different people. These factors are given as challenge and value of work, feedback, support, confidence and commitment which are given as learning factors. There are also context factors which are allocation and structuring of work, expectations and encounters/relationships with people at work. Both this theory and the findings of Ajjawi and Higgs [7] do point to the workplace environment contributing to and being a large factor in learning.

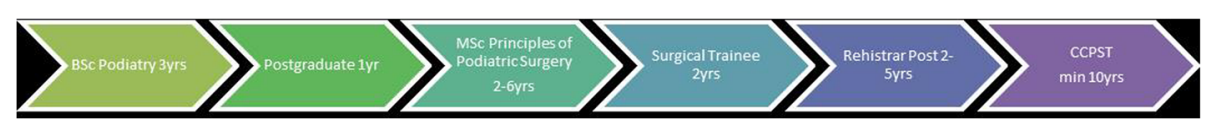

Fig. 1 The podiatric surgery route 
Eraut [6] interestingly does recommend that each organisation assesses their own environment to self-evaluate with a view to trying to create a positive impact on retention, innovation and quality. This is where the podiatric surgical theatre is a key environment that can be evaluated.

The teaching and learning environment utilised for podiatric surgery is both in the classroom and within the work environment including the podiatric surgery theatre. The academic institutions provide the teaching for the 'taught' MSc in Principles of Podiatric Surgery while the podiatric surgeons are given the trainer' responsibilities for the clinical experience and guidance through the surgical trainee and registrar posts.

With more structured processes and within a framework which meets higher governance standards and contributes to the legislative process, under the HCPC, the evidence of quality of the institution guiding the production of new podiatric surgeons is to be monitored.

This appears to be occurring in a collaborative manner within Higher Education Institutions and the NHS to provide a framework from the start to finish of qualification for podiatric surgery. The example given by the HCPC was of NHS Education for Scotland (NES) which has recently developed a three-year, work-based podiatric surgery training programme in collaboration with Queen Margaret University, which will award a certificate of completion of training (CCT). Standards published by the HCPC require demonstration of a number of specific statements (Table 1). During the training examinations do have independent assessors who maintain the aims and objectives of surgery within criteria set by the College. However, it appears the only evidence of monitoring and evaluation that is specific to podiatric surgery is the outcomes of surgical procedures themselves. This is via the PASCOM (Podiatric and Surgical Clinical Outcome Measurement) online system which is aimed at being an audit and outcome tool [8].

The operating theatre has a unique atmosphere and therefore can be seen as a specific environment in which to learn, it provides quality uninterrupted time for the teacher and learner which should be utilised for clinical teaching and learning [9]. Our primary aim was to measure the podiatric surgery theatre as an educational environment currently used by podiatrists, podiatric surgical trainees and podiatric surgery registrars for $\mathrm{CCT}$ in podiatric surgery. This work also seeks to identify elements that contribute to the educational environment, and find areas that may be targeted for improvement.

An inventory for measuring the learning environment in the surgical operating theatre as perceived by basic surgical trainees was created by Cassar at the University of Aberdeen in Scotland [10]. Developed on from the Postgraduate Hospital Educational Environment Measure (PHEEM), this 40-item questionnaire evolved through a literature review and input of surgical trainers and trainees via interviews. The inventory was then validated by being administered to Scottish basic surgical trainees and called the "Surgical Theatre Educational Environment Measure" (STEEM). Thus, the major elements that contribute to the educational environment in the Scottish surgical theatre were determined, and provides a valid assessment tool to identify discrete areas to be targeted for improvement.

This tool has been applied to assess teaching and learning in the surgical environment. It appears this has not been applied to the podiatric surgery theatre. In fact the author could find no literature regarding teaching and learning within the podiatric surgery theatre environment. Given the HCPC standards discussed it is possible this could be used in some part as evaluation of theatre based training.

This research aimed to identify the major elements that contribute to the educational environment, and find and utilise a valid assessment tool which could identify discrete areas to be targeted for improvement as well as being used for monitoring of the environment.

\section{Methods}

\section{Materials and methods}

The STEEM questionnaire consisting of 40 questions was used. Each question had a Likert scale ranging from 4 "strongly agree" to 0 "strongly disagree". A Likert scale $0-4$ has been used due to the possible overestimation of a 1-5 score [11]. Reverse coding of the negative questions; $8,11,14,16,19,22,23,26,27,28,30,31,33,34$, $35,36,37,38$ and 40, was utilised and therefore the higher the score the more positive the perception. A maximum overall score would be of 160 and minimum score of 0 (see Table 2).

\section{Data collection}

A link to Survey Monkey, where the STEEM had been inputted, was emailed via The College of Podiatry to podiatrists registered on a training programme and podiatrists

Table 1 HCPC Statements for podiatric surgery

\begin{tabular}{ll}
\hline B. 3 & The programme must have regular monitoring and evaluation systems in place \\
C. 3 & Integration of theory and practice must be central to the curriculum \\
D. 3 & The practice placement must provide a safe and supportive environment \\
D. 4 & The education provider must maintain a thorough and effective system for approving and monitoring all practice placements \\
\hline
\end{tabular}


Table 2 shows the individual questions median score and interquartile range (IQR) with reverse coded questions marked with an asterix

\begin{tabular}{|c|c|c|}
\hline No. & Statement & Median $(\mathrm{IQR})(N=16)$ \\
\hline 1 & My trainer has a pleasant personality & $4(2.5-4)$ \\
\hline 2 & I get on well with my trainer & $4(2.5-4)$ \\
\hline 3 & My trainer is enthusiastics about teaching & $3.5(3-4)$ \\
\hline 4 & My trainer has a geniune interest & $4(3-4)$ \\
\hline 5 & I understand what my trainer is trying to teach me & $4(3-4)$ \\
\hline 6 & My trainer's surgical skills are very good & $4(3-4)$ \\
\hline 7 & My trainer's gives me time to practice surgical skills in theatre & $4(3-4)$ \\
\hline 8 & My trainer immediately takes the instruments away when I do not perform well * & $3(2-4)$ \\
\hline 9 & Before the operation my trainer discusses the surgical technique planned & $3(1-3)$ \\
\hline 10 & Before the operation my trainer discusses what parts of the procedure I will perform & $2.5(1-4)$ \\
\hline 11 & My trainer expects my surgical skills to be as good as his/hers * & $2(1-3)$ \\
\hline 12 & My trainer gives me feedback on my performance & $3.5(3-4)$ \\
\hline 13 & My trainer's criticism is constructive & $3(2.4)$ \\
\hline 14 & On this unit the type of operations are too complex for my level * & $3.5(3-4)$ \\
\hline 15 & The elective operating list has the right case mix to suit my training & $4(3-4)$ \\
\hline 16 & There are far too many cases on the elective list to give me opportunity to operate * & $3(2-4)$ \\
\hline 17 & I get enough opportunity to assist & $4(4-4)$ \\
\hline 18 & There are enough theatre sessions per week for me to gain the appropriate experience & $4(2.5-4)$ \\
\hline 19 & More senior trainees take my opportunities to operate ${ }^{*}$ & $2.5(2-4)$ \\
\hline 20 & The number of emergency procedures is sufficient for me to gain the appropriate experience & $2(2-2.5)$ \\
\hline 21 & The variety of emergency cases gives me the appropriate exposure & $2(2-3)$ \\
\hline 22 & My trainer is in too much of a rush during emergency cases to let me operate & $2(2-3)$ \\
\hline 23 & I miss out on operative experience because of restrictions on working hours * & $3(2.5-4)$ \\
\hline 24 & I have the opportunity to develop my skills required at my stage & $3(2.5-4)$ \\
\hline 25 & The atmosphere in theatre is pleasant & $4(3-4)$ \\
\hline 26 & In theatre I don't like being corrected in front of medical students, nurses and residents * & $4(3-4)$ \\
\hline 27 & The nursing staff dislike it when I operate as the operation takes longer * & $3.5(2-4)$ \\
\hline 28 & The anaesthetists put pressure on my trainer to operative him/herself to reduce anaesthetic time * & $4(2-4)$ \\
\hline 29 & The theatre staff are friendly & $4(3-4)$ \\
\hline 30 & I feel discriminated against in theatre because of my sex * & $4(3.5-4)$ \\
\hline 31 & I feel discriminated against in theatre because of my race ${ }^{*}$ & $4(4-4)$ \\
\hline 32 & I feel part of a team in theatre & $4(3-4)$ \\
\hline 33 & I am too busy doing other work to go to theatre & $4(2-4)$ \\
\hline 34 & I am often too tired to get the most out of theatre teaching * & $4(2-4)$ \\
\hline 35 & I am so stressed in theatre that I do not learn as much as I could * & $4(3-4)$ \\
\hline 36 & I am asked to perform operations alone that I do not feel competant at * & $4(3.5-4)$ \\
\hline 37 & When I am in theatre, there is nobody to cover the ward & $4(2-4)$ \\
\hline 38 & I get bleeped during operations * & $4(2-4)$ \\
\hline 39 & The level of supervision in theatre is adequate for my level & $4(3-4)$ \\
\hline 40 & Theatre sessons are too long * & $4(3-4)$ \\
\hline
\end{tabular}


working towards the Certificate of Completion of Podiatric Surgery Training (CCPST).

\section{Subjects and setting}

The College of Podiatry was asked to facilitate the communication to registered trainees and registrars. This included the Deanery of Podiatric Surgery (North, Midlands and South). The inclusion and exclusion criteria were considered by the College of Podiatry, UK. This was for the attention of "podiatrists training or working within a podiatric surgery unit" as well as stating the survey cannot be completed by anyone who holds the Certificate of Completion of Podiatric Surgery Training.

As such, the database allowed the email to be sent to members who were: registered as a podiatric surgical trainee (25 email addresses) registrars (8 email addresses) which resulted in 33 eligible people on the records of the College of Podiatry.

\section{Data analysis}

Statistics were used to report the median and interquartile ranges. Within the STEEM there are 4 subscales 'Teaching and training,' 'Learning Opportunities', 'Atmosphere' and 'Supervision/workload/support' which is analysed with descriptive statistics utilising graphic representation. The highest and lowest scored statements was noted and discussed within the context of podiatric surgery. Comparisons are made against the original Cassar [10] study and the most recent Binsaleh [12] study.

\section{Results}

Sixteen out of thirty three responded. The overall score was a total of 1952 out of a maximum 2544 with a mean score of $122 / 160$, as a percentage this is $67.73 \%$. Figure 1 shows the median and interquartile range for each statement in the STEEM survey for the whole group $(n=16)$.
The scores of subscales are depicted in Fig. 2 which shows the percentage scores for the whole group and individual subscales. The highest percentage score was given to the Atmosphere subscale with 427 out of 508 meaning an $84 \%$ score. The lowest score was given to Learning Opportunities with 490 out 692 which means a $70.8 \%$ score.

The most highly rated statements by the whole group were no. 17 "I get enough opportunity to assist", no. 31 "I feel discriminated against in theatre because of my race", no. 30 "I feel discriminated against in theatre because of my sex" and no. 36 "I am asked to perform operations alone that I do not feel competent at". The medians were 4 , and IQR were 4-4 and 3.5-4 respectively.

The lowest rated statements were no. 11 "My trainer expects my surgical skills to be as good as his/hers". No. 20 "The number of emergency procedures is sufficient for me to gain the right operative experience", no.21 "The variety of emergency cases gives me the appropriate exposure" and no. 22 "My trainer is in too much of a rush during emergency cases to let me operate". The medians were 2 , and IQR were $1-3,2-2.5,2-3$ and $2-3$ respectively.

\section{Discussion}

The overall score of the study 122/160 (76.73\%) demonstrates an overall satisfaction of the respondents. Using Likert's [13] scale a score over $60 \%$ indicates a satisfactory learning environment but would aim for a very satisfactory score which would be $80 \%$ or higher. It has been suggested by Binsaleh [12] that a score less than $80 \%$ represents a learning environment that is less than agreeable, as it corresponds to a score lying between that of uncertain $(60 \%)$ and agree $(80 \%)$ on Likert's non parametric scale. The Likert scale itself has shown to be a robust tool for parametric data however the sensitivity

\section{\% Score}

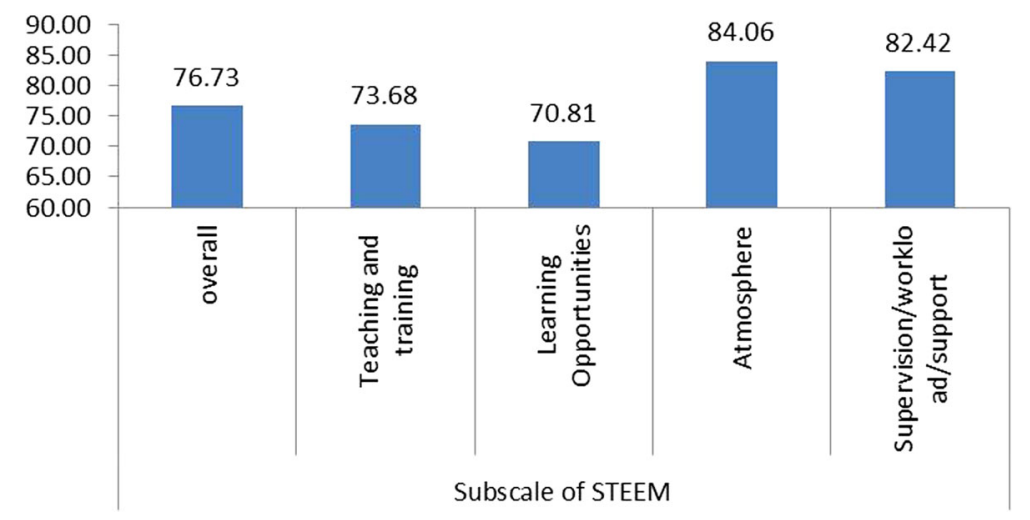

Fig. 2 Overall percentage score and percentage scores for individual subscales for the whole group $(N=16)$ 
of then analysing the outcome has proven to be more challenging [14].

Table 3 shows a comparison between the current study and selected studies from the literature review. All the data has been adjusted to a $0-4$ Likert scale to enable a true comparison which negates the overestimation of a 15 scale as recommended by Dimoliatis [11]. The current study does compare favourably to these studies which all have an overall score of less than $70 \%$ whereas the podiatric surgery learning environment shows a $76.73 \%$ agreement of a satisfactory environment. Cassar [10] in the original STEEM study suggests that his overall score of $67.9 \%$ showed a 'satisfactory' learning environment, however no reference was given as to how they came to deciding it was satisfactory. Therefore we can suggest that the current study demonstrates a satisfactory learning environment across the UK within podiatric surgery.

Subscales showed the Learning Opportunities as being the least satisfied for podiatric surgical trainees at $70.81 \%$. However this appears to be a relatively good score compared to the other studies notably Cassar [10] and Binsaleh [12] being below $60 \%$. There is a trend however across all the studies that this subscale is the one that is scored lowest. It is interesting to note the highest scored question is Q 17 "I get enough opportunity to assist" however the three of the lowest scored questions, Q 20, Q 21 and Q 22 "The number of emergency procedures is sufficient for me to gain the right operative experience", "The variety of emergency cases gives me the appropriate exposure" and "My trainer is in too much of a rush during emergency cases to let me operate" contribute to the low Learning opportunities score as they have been scored poorly. It can be suggested these questions are inappropriate for podiatric surgery as the typical caseload is elective day case surgery [15]. It would seem appropriate to consider the meaning of emergency procedures within podiatric surgery and possibly remove these questions for future studies however the tool would require re-validation.
The strongest subscale was shown to be the 'Atmosphere' subscale and this is reflected across most of the previous studies. The Cassar [10] study however showed the 'Teaching and Training' to be the strongest. The strongest individual statements within the current study reflect this with Q 31 "I feel discriminated against in theatre because of my race" and Q 30 "I feel discriminated against in theatre because of my sex" highlighting the non-discriminatory atmosphere felt by the participants within the surgical theatre.

This study demonstrates that discrimination is scored very low. However Fnais et al. [16] in 2011 did a thorough systemic review and meta-analysis of discrimination and harassment within the medical trainee population showing it was still "surprisingly high". This did suggest that the 'consultant' was the most commonly cited source for harassment and discrimination however this did include patient harassment towards the medical trainee.

The current study tries to reflect the podiatric surgery community within the UK and is potentially limited by the small sample size. In comparing the other studies that have utilised the STEEM there is a 'like for like' process. However it should be noted the working environment as well as the training within podiatric surgery is different to that of the medical specialities. Podiatric surgery units can operate within an acute setting, community setting or a mixture of the two and this would be of further interest in the future.

Either at a national or individual level, the studies can be utilised to assess the current situation of the learning environment, reflect what current students perceptions are and be used to compare to each other. This does potentially reflect each speciality and gives a comparison as to whether each speciality is giving a better or worse learning environment for the future of their profession. It may be that the current study has an advantage being contemporary as learning from previous studies and

Table 3 Comparison between the current study and selected studies from the literature review

\begin{tabular}{llllll}
\hline Variable & Cassar (2004) & Kanashiro (2006) & Mahony (2010) & Binsaleh (2015) & Current study \\
\hline sample size & 25 & 22 & 356 & 33 & 16 \\
Response rate & $25 / 26(96 \%)$ & $22 / 23(95.6 \%)$ & $356 / 1500(24 \%)$ & $33 / 72(45.8 \%)$ & $16 / 33(48.4 \%)$ \\
Overall STEEM mean score & $108 / 160$ & $107 / 160$ & $107.6 / 160$ & $95.9 / 160$ & $122 / 160$ \\
STEEM \% score & $67.90 \%$ & $67.00 \%$ & $67.30 \%$ & $59.93 \%$ & $76.73 \%$ \\
Subscale \% Score & & & & $58.84 \%$ & $73.68 \%$ \\
$\quad$ Teaching and training & $73.60 \%$ & $66.30 \%$ & $65.00 \%$ & $57.95 \%$ & $70.81 \%$ \\
$\quad$ Learning opportunities & $59.40 \%$ & $65.70 \%$ & $65.00 \%$ & $67.81 \%$ & $84.06 \%$ \\
$\quad \begin{array}{l}\text { Atmosphere } \\
\text { Supervision/workload/support }\end{array}$ & $70 \%$ & $72.30 \%$ & $72.50 \%$ & $56.56 \%$ & $82.42 \%$ \\
& $68.80 \%$ & $59.40 \%$ & $68.80 \%$ & Urology & Podiatric Surgery \\
\hline
\end{tabular}


teaching and learning theories should hopefully advance over time giving better outcomes.

The original Cassar [10] study being 12 years ago will have set useful data for future studies to be able to compare to. It has been considered that participants may have some bias reporting on their own centre. However this bias has been mitigated for in utilising an anonymous survey.

\section{Conclusions}

Perception was of a very satisfactory 'Atmosphere' within the theatre environment and a very satisfactory 'opportunity to assist' within the podiatric surgery Theatre environment. The results from this study can potentially be utilised within the monitoring and evaluation of the podiatric surgical theatre, to demonstrate a positive and supportive learning environment and potentially enhance the knowledge of the strengths and weaknesses within the learning environment.

This study provides clear evidence that the surgical trainee's perception is one of a positive learning environment which includes being safe and supportive.

\section{Abbreviations}

CCPST: Certificate of Completion of Podiatric Surgery Training; HCPC: Health and Care Professions Council; IQR: Interquartile Range; STEEM: Surgical

Theatre Educational Environment Measure

\section{Acknowledgements}

Thanks to those that completed the questionnaire and to The College of Podiatry for facilitating the process. Thanks should also be given to Mr. S Cahill for reviewing this manuscript.

\section{Funding}

No funding was sought for this research; however it was supported by the University of Brighton.

\section{Availability of data and materials}

All data generated or analysed during this study are included in this published article.

\section{Authors' contributions}

TA wrote this paper from his MSc dissertation thesis. SO was a major contributor in supervising the submission. All authors read and approved the final manuscript.

\section{Ethics approval and consent to participate}

University of Brighton school of health sciences research ethics and governance committee ethics approval was sought and granted. Permission of participants and The College of Podiatry was sought and granted by the Dean of podiatric surgery.

Consent for publication not applicable.

\section{Competing interests}

The authors declare that they have no competing interests.

\section{Publisher's Note}

Springer Nature remains neutral with regard to jurisdictional claims in published maps and institutional affiliations.

\section{Author details}

'Podplus Ltd, The Julie Rose Stadium, Ashford, Kent TN24 9QX, UK. ${ }^{2}$ School of Health Sciences, University of Brighton, Robert Dodd, Darley Road, Eastbourne BN20 7UR, UK. ${ }^{3}$ School of Health Sciences, University of Brighton, Robert Dodd, Darley Road, Eastbourne BN20 7UR, UK.
Received: 17 May 2018 Accepted: 25 December 2018

Published online: 15 January 2019

\section{References}

1. Health and Care Professions Council 2016 Standards for podiatric surgery. Published 01-06-2015 accessed 25 Aug 2016 http:/www.hcpc-uk.org/ publications/standards/index.asp?id $=1060$

2. Manuti, A., Pastore, S., Scardigno, A., Giancaspro, M., Morciano, D. (2015) Formal and informal learning in the workplace: a research review. Int J Train Dev Feb 19:1 1-17.

3. Cofer DA. "Informal workplace learning (practice application brief no. 10)", ERIC clearinghouse on adult, career, and vocational education, Columbus, $\mathrm{OH} ; 2000$.

4. Eraut M. Non-formal learning and tacit knowledge in professional work. Br J Educ Psychol. 2000;70:113-36.

5. Beckett D, Hager P. Life, work and learning: practice in post-modernity. London: Routledge; 2002.

6. Eruat M. Informal learning in the workplace. Stud Contin Educ. 2004;26(2):247-73,

7. Ajjawi, R and Higgs J. (2007) Using Hermeneutic Phenomenology to Investigate How Experienced Practitioners Learn to Communicate Clinical Reasoning. Qual Rep Volume 12 Number 4 December 612-638.

8. Society of Chiropodists and Podiatrists 2016 College of Podiatry PASCOM10. Accessed 1 Sept 2016 http://www.pascom-10.com/about-pascom-10

9. Scallon S, Fairholme D, Cochrane D, Taylor D. Evaluation of the operating room as a surgical teaching venue. Can J Surg. 1992) Apr;35(2):173-6.

10. Cassar K. Development of an instrument to measure the surgical operating theatre learning environment as perceived by basic surgical trainees. Medical Teacher. 2004;26:260-4.

11. Dimoliatis, I and Jelastopulu, E. (2013) Surgical theatre (operating room) measure STEEM (OREEM) scoring Overeastimates educational nvironment: the 1-to-L Bias. Univ J Educ Res 1(3): 247-254, 2013.

12. Binsaleh S, Babaeer A, Rabah D, Madbouly K 2015 Evaluation of urology residents' perception of surgical theatre educational environment. I Surg Educ 2015 Jan-Feb;72(1):73-79.

13. Likert R. A technique for measurement of attitudes. Arch Psychol. 1932;140: 44-53 1932 In: Berk, R. Thirteen strategies to measure college teaching. Stylus Publishing LLC, Sterling, Virginia, USA.

14. Norman G. Likert scales, levels of measurement and the "laws" of statistics. Adv in Health Sci Educ. 2010;15:625.

15. Rudge G, Tollafield D. A critical assessment of a new evaluation tool for podiatric surgical outcome analysis. Br J Podiatry. 2003;6(4):109-19.

16. Fnais, N., Soobiah, C., Chen, M., Lillie, E., Perrier, L., Tashkhandi, M., Straus, S., Mamdani, M., Al-Omran, M., Tricco, A. (2014) Harassment and discrimination in medical training: a systematic review and meta-analysis. Acad Med: May 2014 - Volume 89 - Issue 5 - p 817-827.

Ready to submit your research? Choose BMC and benefit from:

- fast, convenient online submission

- thorough peer review by experienced researchers in your field

- rapid publication on acceptance

- support for research data, including large and complex data types

- gold Open Access which fosters wider collaboration and increased citations

- maximum visibility for your research: over 100M website views per year

At BMC, research is always in progress.

Learn more biomedcentral.com/submissions 